\title{
Active surveillance for prostate cancer: a systematic review of contemporary worldwide practices
}

\author{
Netty Kinsella ${ }^{1,2}$, Jozien Helleman ${ }^{3}$, Sophie Bruinsma ${ }^{3}$, Sigrid Carlsson ${ }^{4,5,6}$, Declan Cahill ${ }^{2}$, Christian \\ Brown $^{7,8}$, Mieke Van Hemelrijck ${ }^{1}$ \\ ${ }^{1}$ Translational Oncology \& Urology Research (TOUR), School of Cancer and Pharmaceutical Sciences, King's College London, London, UK; \\ ${ }^{2}$ Department of Urology, the Royal Marsden Hospital, London, UK; ${ }^{3}$ Department of Urology, Erasmus University Medical Center, Rotterdam, the \\ Netherlands; ${ }^{4}$ Department of Surgery, ${ }^{5}$ Department of Epidemiology and Biostatistics, Memorial Sloan Kettering Cancer Center, New York, USA; \\ ${ }^{6}$ Department of Urology, Institute of Clinical Sciences, Sahlgrenska Academy at Gothenburg University, Gothenburg, Sweden; ${ }^{7}$ Department of \\ Urology, King's College Hospital, London, UK; ${ }^{8}$ Department of Urology, Guy's and St Thomas' Hospital, London, UK \\ Contributions: (I) Conception and design: N Kinsella, M Van Hemelrijck, J Helleman; (II) Administrative support: N Kinsella, M Van Hemelrijck; (III) \\ Provision of study material or patients: N Kinsella, M Van Hemelrijck; (IV) Collection and assembly of data: N Kinsella, J Helleman, S Bruinsma; (V) \\ Data analysis and interpretation: N Kinsella, J Helleman, S Bruinsma, M Van Hemelrijck; (VI) Manuscript writing: All authors; (VII) Final approval \\ of manuscript: All authors. \\ Correspondence to: Netty Kinsella. Translational Oncology \& Urology Research (TOUR), School of Cancer and Pharmaceutical Sciences, King's \\ College London, London, UK; Department of Urology, The Royal Marsden Hospital, London, UK. \\ Email: jkinsella1972@gmail.com; netty.kinsella@rmh.nhs.uk.
}

\begin{abstract}
In the last decade, active surveillance (AS) has emerged as an acceptable choice for low-risk prostate cancer (PC), however there is discordance amongst large AS cohort studies with respect to entry and monitoring protocols. We systematically reviewed worldwide AS practices in studies reporting $\geq 5$ years follow-up. We searched PubMed and Medline 2000-now and identified 13 AS cohorts. Three key areas were identified: (I) patient selection; (II) monitoring protocols; (III) triggers for intervention-(I) all studies defined clinically localised PC diagnosis as T2b disease or less and most agreed on prostate-specific antigen (PSA) threshold $(<10 \mu \mathrm{g} / \mathrm{L})$ and Gleason score threshold $(3+3)$. Inconsistency was most notable regarding pathologic factors (e.g., number of positive cores); (II) all agreed on PSA surveillance as crucial for monitoring, and most agreed that confirmatory biopsy was required within 12 months of initiation. No consensus was reached on optimal timing of digital rectal examination (DRE), general health assessment or re-biopsy strategies thereafter; (III) there was no universal agreement for intervention triggers, although Gleason score, number or percentage of positive cancer cores, maximum cancer length (MCL) and PSA doubling time were used by several studies. Some also used imaging or re-biopsy. Despite consistent high progression-free/cancer-free survival and conversion-to-treatment rates, heterogeneity exists amongst these large AS cohorts. Combining existing evidence and gathering more long-term evidence [e.g., the Movember's Global AS database or additional information on use of magnetic resonance imaging (MRI)] is needed to derive a broadly supported guideline to reduce variation in clinical practice.
\end{abstract}

Keywords: Active surveillance (AS); cohort study; prostate cancer (PC)

Submitted Dec 11, 2017. Accepted for publication Dec 18, 2017.

doi: $10.21037 /$ tau.2017.12.24

View this article at: http://dx.doi.org/10.21037/tau.2017.12.24 


\section{Introduction}

Prostate cancer (PC) is the second most common cancer diagnosis and the fifth leading cause of cancer mortality in men (1). In 2012, 1.09 million men were diagnosed worldwide, thus representing a substantial public health burden. The use of prostate specific antigen (PSA) testing and improvements in diagnostic procedures such as imaging and ultrasound guided biopsy have led to a significant increase in early diagnosis of localized, low-risk PC (LRPC), ranging from 10-80\% of all men diagnosed with PC worldwide (1), and a subsequent decrease in PC mortality (2-4).

A substantial proportion of men with LRPC do not need treatment with surgery or radiation, but can be carefully monitored-an approach known as active surveillance (AS). Overtreatment of LRPC is of concern, not only because of the physical and psychological morbidity associated with radical treatment, but also because of the economic healthcare burden $(5,6)$. AS is considered a safe alternative to immediate treatment and is endorsed by national medical organizations and guideline groups as a viable management option for men with LRPC (7).

More specifically, AS for LRPC can be defined as a treatment strategy of close monitoring through blood tests (PSA), digital rectal examination (DRE), imaging and prostate biopsy, with conversion to curative treatment if progression occurs $(8,9)$. Large cohort studies have shown that with appropriate patient selection, risk of dying from PC in men on AS is low: $0.1 \%$ to $5.7 \%$ over 10-15 years (Table 1). However, inconsistency in selection and adherence to AS remains. Studies suggest that patient preference $(23,24)$, physician $(25,26)$, family and peer group influence $(27,28)$, National guidelines $(29,30)$ and local practices $(31,32)$ all influence this process. There is also no doubt that anxiety surrounding disease progression also plays a significant role (33-35) in influencing longterm AS adherence. It is reported that cancer continues to cause more fear than debt, knife crime, Alzheimer's disease and unemployment (36). Unsurprisingly therefore, studies continue to report that $1.6 \%$ to $38 \%$ of men opt out of AS often with no or little evidence of disease progression within 5 years (Table 1).

However, in the last 10 years a trend towards AS adoption in LRPC has been reported by many large database studies, with some variation still noted between countries, practices and physicians (37). Most notable are the upward trends seen in North America, Australia and Europe. In 2015,
Cooperberg and Carroll reviewed US trends in AS reporting from the US CaPSURE (Cancer of the Prostate Strategic Urologic Research Endeavor) database. This demonstrated a sharp rise in the uptake of AS, from $10 \%$ over the past 20 years to $40 \%$ in $2010-2013$ (4). This was replicated in Europe with the Swedish National PC Register reporting a rise from $40 \%$ to $74 \%$ between 2009 and 2014 (30) and in Australia, where the Victorian PC Registry (38) reported a $16 \%$ rise in AS uptake between the first half of 2010 and second half (23.9\% to $39.7 \%)$. This level (39\%) was maintained over the following 2 years further increasing in 2015 up to $42.8 \%$ (39). This was also demonstrated in hospitals reporting on radical prostatectomy in both Canada and Germany. In Canada (Toronto), Louis and authors (40) reported a steady decline in the number of radical prostatectomies carried out for LRPC from 2007 (40.6\%) to 2012 (13.6\%), whilst in Germany the Martini Clinic (41) demonstrated a similar decrease for low-risk Gleason score 6 cancer in $2014(12.1 \%)$ in comparison to $52.2 \%$ in 2000 .

However, this increase is not universal. In contrast, a 2014 survey (42) of 2,133 Japanese urologists suggested that $26.9 \%$ reported no use of AS for LRPC and another 50.6\% reported using AS in $<5 \%$ of their patients. Moreover, only $27 \%$ of respondents indicated that they would want to offer AS more frequently in the future.

The increased use of AS seen in some countries suggests that the global trend towards conservative management for LRPC is gathering pace, however the fact that there is no worldwide consensus on defining favourable risk disease (43) in AS suggests that there is still some way to go in gaining universal acceptance.

This review aims to evaluate the literature describing contemporary AS practices worldwide and explores the importance of Movember's GAP3 (Global Action Plan Prostate Cancer-Active Surveillance) collaborative effort in answering the key questions: what defines safe patient selection? What should the surveillance strategy look like? What clinical triggers are important in recommending radical treatment?

\section{Search strategy}

Studies documenting AS cohorts with a minimum of 5 years' follow-up published before October 2017 were identified through a systematic search of electronic databases (PubMed/Medline 2000-now and Embase) using the following key search terms: "prostate cancer", "active surveillance", "follow-up", "cohort", and their relevant 


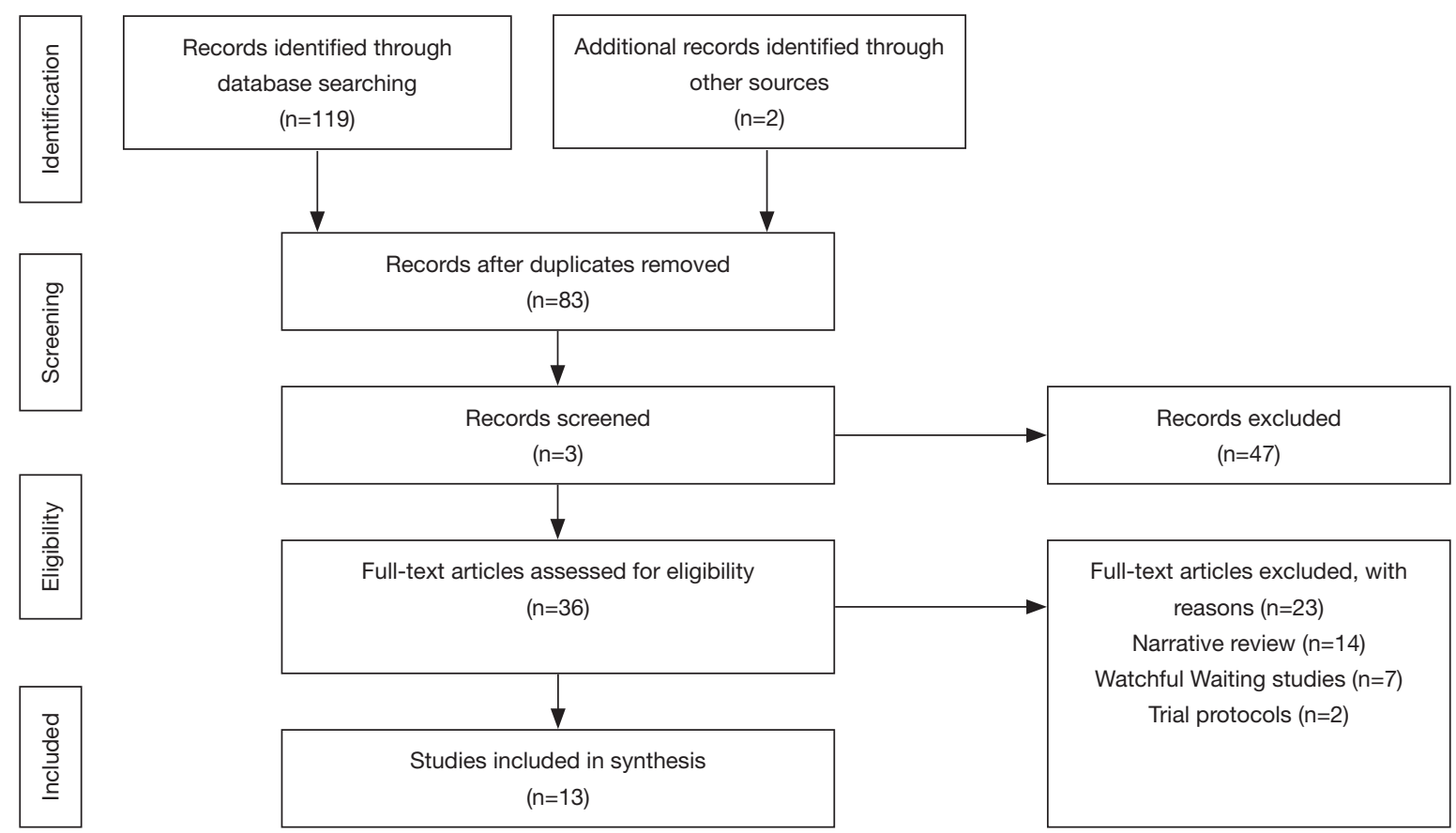

Figure 1 Preferred reporting items for systematic reviews and meta-analysis (PRISMA) flow diagram.

synonyms. Cited references were searched and retrieved for potentially eligible publications.

Studies of primary interest were those describing baseline and clinical characteristics of the study population, patient selection criteria, monitoring/surveillance protocol, AS drop-out, triggers for conversion to radical treatment and outcomes during follow-up (5-year studies with a median follow-up $>18$ months).

\section{Findings}

We identified 119 unique citations; of these 83 were excluded as review articles, commentaries, narratives, abstracts or where median follow-up was less than 18 months. Full-text screening was carried out on 36 articles, of which 23 were excluded, rendering 13 articles included (Figure 1-PRISMA diagram) each describing a unique AS cohort. Of the 13 included cohort studies (10-22), 6 took place in North America (10-12,14,17,21), 5 in Europe $(15,16,18,20,22), 1$ worldwide (13) and 1 in Australia (19).

The general demographic and follow-up characteristics of the published AS cohorts in this review vary considerably (Table 1). The average age across the studies was 65 years old. The number of participants studied ranged from 238 to
2,494 men. The number of months' follow-up ranged from 19 to 180 months.

The main findings in terms of AS adoption/patient selection, monitoring protocols and trigger points for intervention or re-assessment across the different AS studies are described below.

\section{AS patient selection}

Thirteen international AS programmes met our inclusion criteria, describing guidelines for AS patient selection (Table 2). These are described with respect to selection criteria based on the following components: (Tumour Nodes Metastases) TNM stage, PSA level, PSA density, percentage of cancer in prostate cores, number of positive cores and Gleason grading.

\section{TNM stage}

All cohorts agreed eligibility for AS meant clinically localised PC, with half of the cohorts using T2a or less, two [John Hopkins (11) and Goteborg (20)] opting to follow the Epstein criteria of T1c (in at least one arm of their cohort study). At the other end of the spectrum, three studies also included patients with T2b [(St Vincent's, Australia (19), Canary PASS (21) and Milan (22)] and two cohorts men diagnosed 


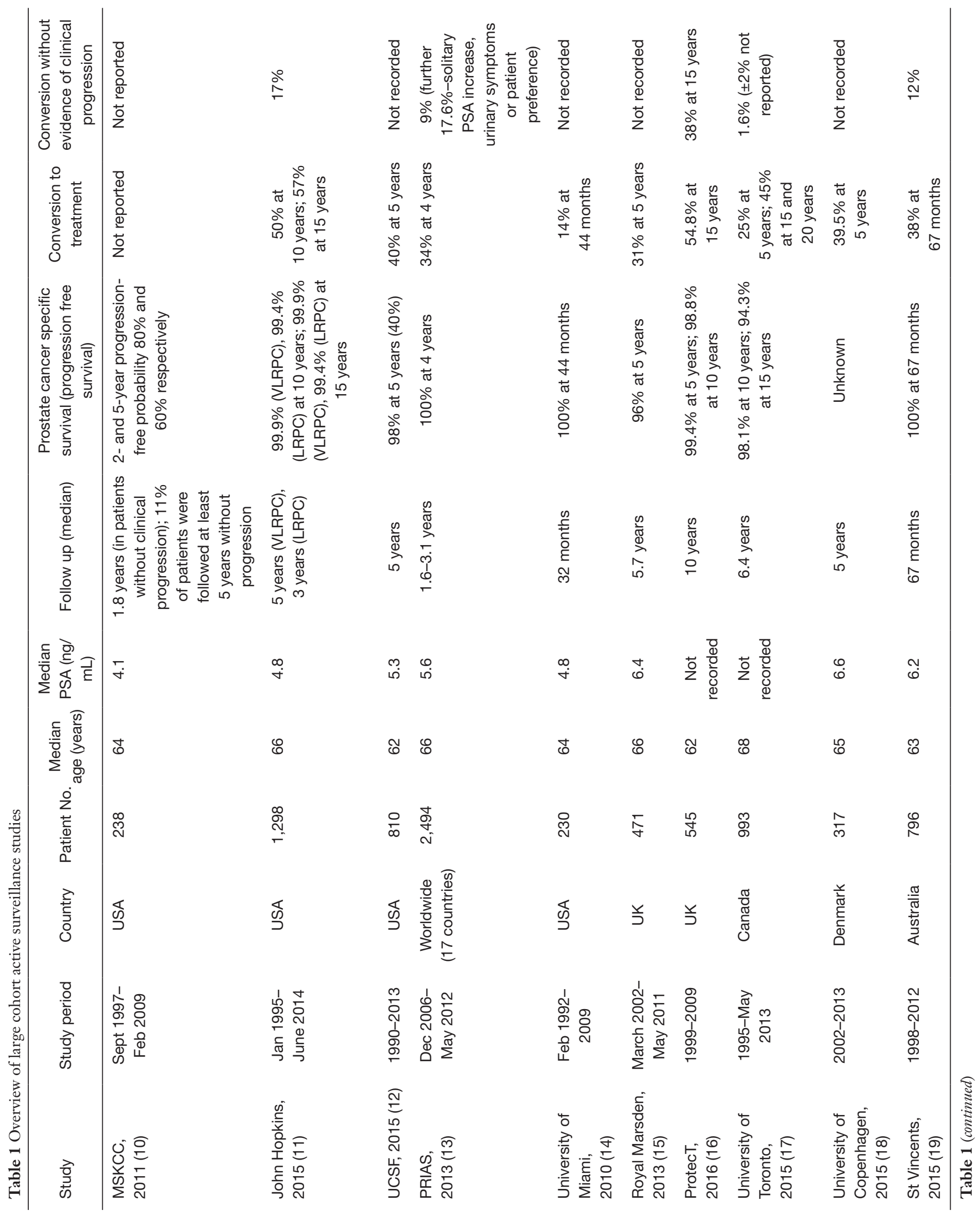




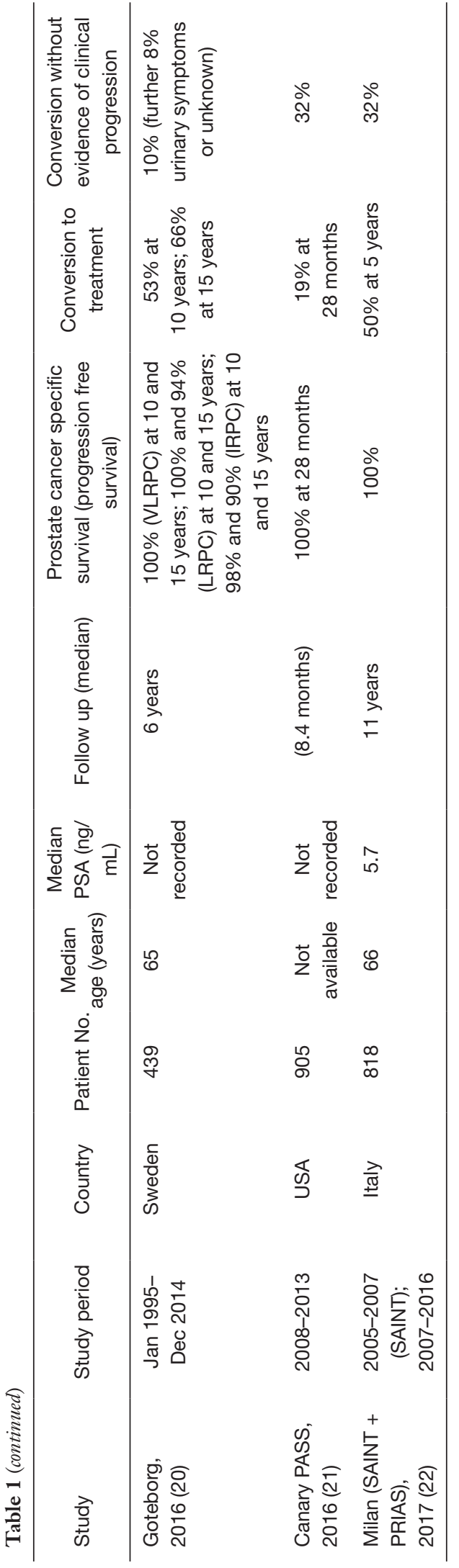

with T2c disease [Canary PASS (21) and Milan (22)].

\section{PSA level}

Agreement between ten of thirteen cohorts suggested a PSA cut-off of $10 \mu \mathrm{g} / \mathrm{L}$, the University of Toronto (17) and Royal Marsden (15) suggested an upper limit of 15-20 $\mu \mathrm{g} / \mathrm{L}$ depending on life expectancy and age ( $>65$ years) respectively. Only Goteborg (20) and Canary PASS (21) suggested an acceptable PSA for intermediate-risk disease of $<20 \mu \mathrm{g} / \mathrm{L}$.

\section{PSA density}

PSA density was featured in five cohorts $(11,13,20-22)$. However, there was no consensus, with Milan (22) and PRIAS (13) suggesting a cut off of 0.2 and John Hopkins (11), Goteborg (20) and Canary PASS (21) opting for a more conservative 0.15 .

\section{Gleason grading}

All included cohorts defined entry into AS as men with lowrisk disease-Gleason $3+3$ or less. The Canary PASS (21) and Goteborg cohorts (20) defined an entry criteria for men with intermediate-risk disease as Gleason 3+4, whereas The Royal Marsden (15) suggested men over the age of 65 were acceptable for entry into AS with Gleason 3+4.

\section{Number of positive cancer cores}

There was more agreement between institutions on the number of positive cancer cores (11 cohorts), which ranged between 2 and 3 cores in most cases. University of California San Francisco (UCSF) (12) suggested the number of cores should not exceed $33 \%$ of the total number of cores taken and the St. Vincent's Australia (19) cohort criteria suggested $20 \%$ as a reasonable cut-off.

\section{Percentage of cancer in prostate core}

Five of thirteen cohorts [Memorial Sloan Kettering Cancer Center (MSKCC) (10), Johns Hopkins (11), UCSF (12), Royal Marsden (15) and Milan (22)] agreed that no prostate core should contain more than $50 \%$ cancer with three cohorts [University of Miami (14), St Vincent's Australia (19) and Canary PASS (21)] suggesting a more conservative 20$34 \%(14,19)$. Five cohorts made no mention of percentage of $\mathrm{PC}$ in cores and therefore it is assumed this was not part of their selection criteria.

\section{Monitoring protocols (Table 3)}

Following initiation of an AS programme, most guidelines 


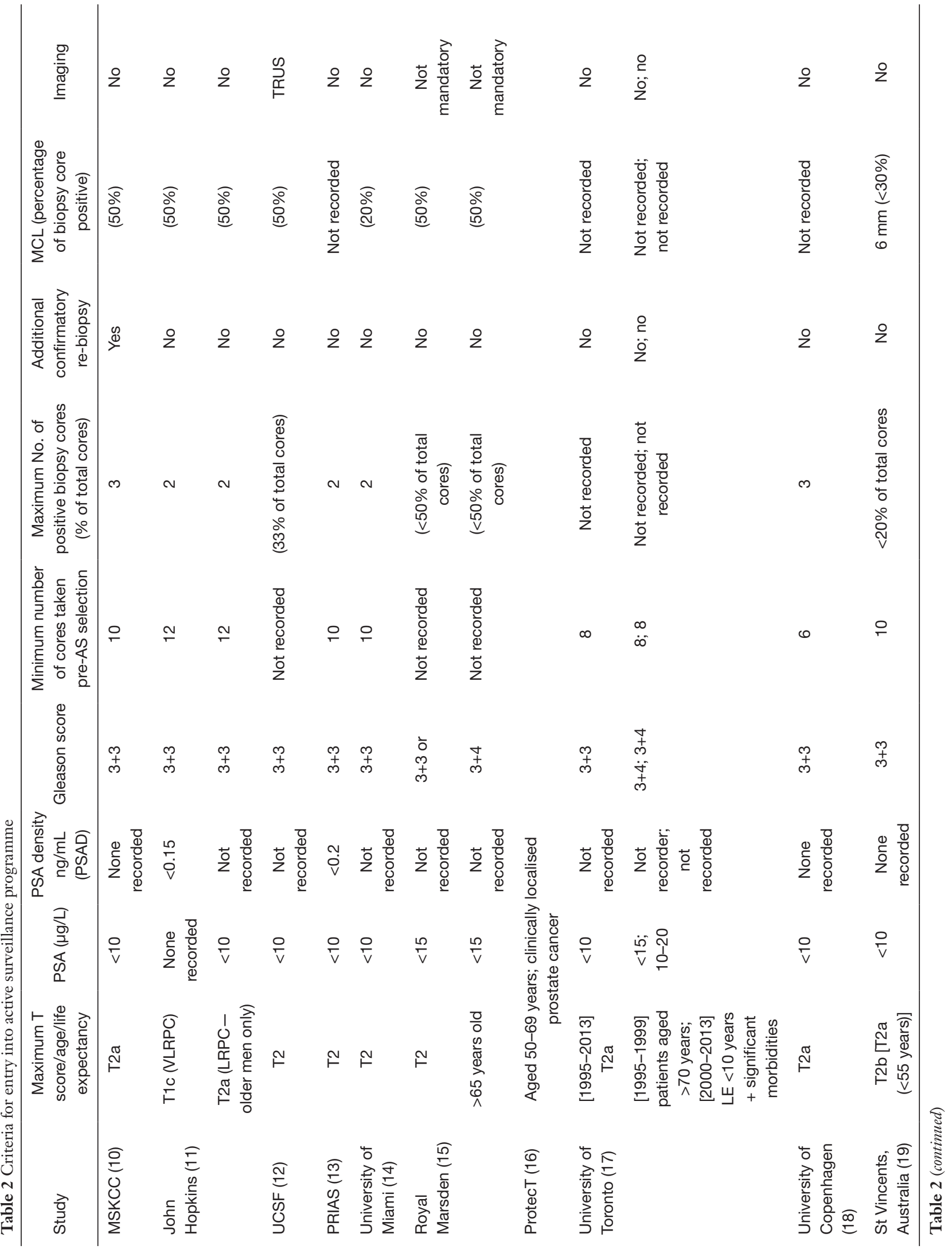




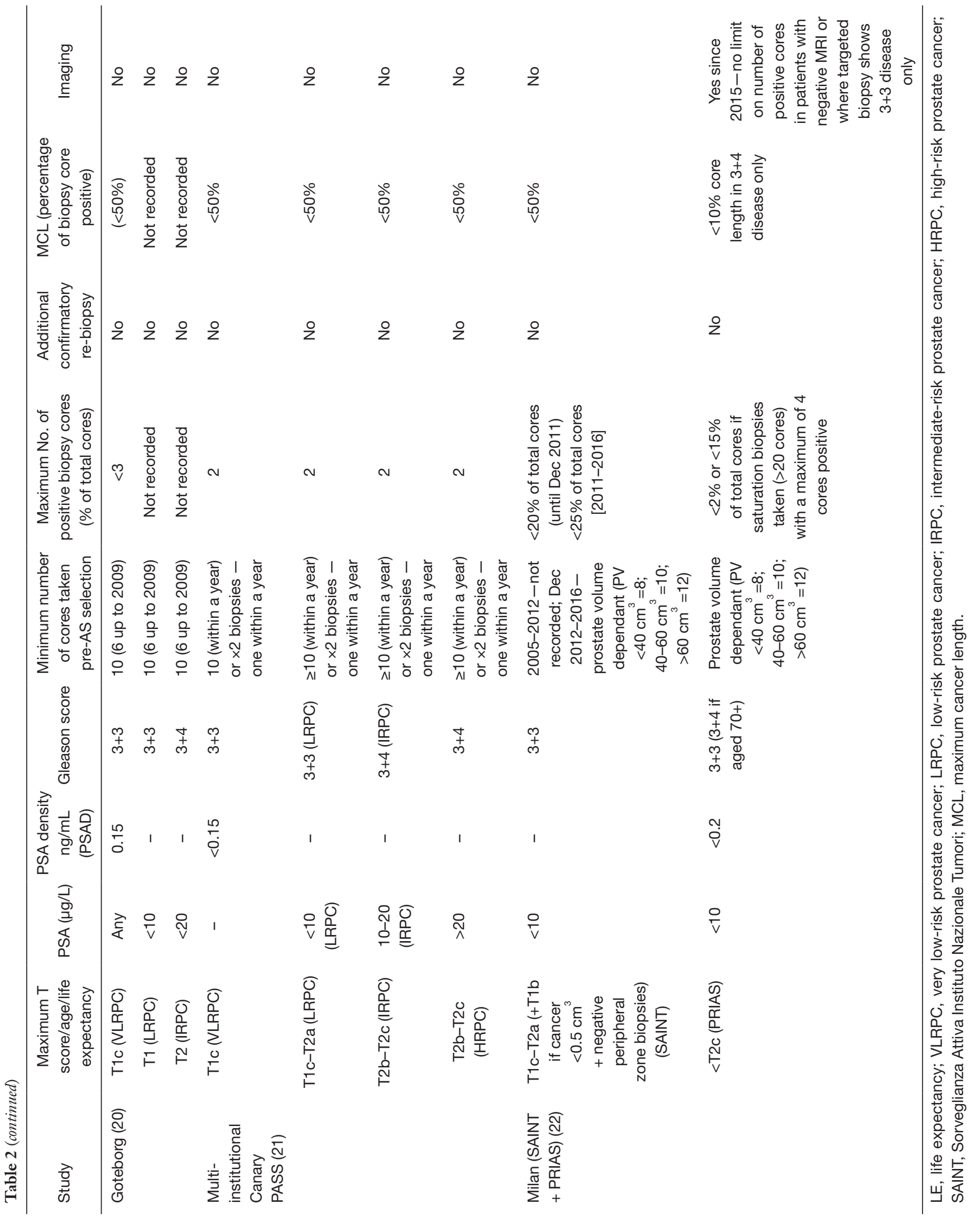


Table 3 Surveillance strategy

\begin{tabular}{|c|c|c|c|c|c|c|c|c|c|}
\hline Study & $\begin{array}{c}\text { DRE } \\
\text { (frequency } \\
\text { in months) }\end{array}$ & $\begin{array}{c}\text { PSA } \\
\text { (frequency } \\
\text { in months) }\end{array}$ & $\begin{array}{l}\text { Free to total } \\
\text { ratio PSA } \\
\text { (frequency } \\
\text { in months) }\end{array}$ & $\begin{array}{c}\text { General } \\
\text { health } \\
\text { assessment }\end{array}$ & $\begin{array}{c}\text { Urinary } \\
\text { symptoms } \\
\text { assessment }\end{array}$ & Imaging & $\begin{array}{c}\text { Number of } \\
\text { biopsy cores }\end{array}$ & $\begin{array}{c}\text { 1st re- } \\
\text { biopsy } \\
\text { scheduled } \\
\text { (frequency } \\
\text { in months) }\end{array}$ & $\begin{array}{l}\text { Follow- } \\
\text { up biopsy } \\
\text { schedule }\end{array}$ \\
\hline MSKCC (10) & $6 / 12$ & $6 / 12$ & $6 / 12$ & Yes & Yes & - & $10-12$ & $12-18 / 12$ & $\begin{array}{c}\text { Every } 2-3 \text { years } \\
\text { or change in } \\
\text { DRE/sustained } \\
\text { PSA rise }\end{array}$ \\
\hline $\begin{array}{l}\text { John } \\
\text { Hopkins (11) }\end{array}$ & $6 / 12$ & $6 / 12$ & - & - & - & - & 12 & $12 / 12$ & Annually \\
\hline UCSF (12) & $6 / 12$ & $3 / 12$ & - & - & - & $\begin{array}{l}\text { TRUS } \\
6 / 12\end{array}$ & 12 & $9 / 12$ & Every $1-2$ years \\
\hline $\begin{array}{l}\text { University of } \\
\text { Miami (14) }\end{array}$ & $\begin{array}{c}\text { 3-4/12 } \\
\text { (2 years) } \\
\text { then } 6 / 12\end{array}$ & $\begin{array}{l}3-4 / 12 \text { (up } \\
\text { to } 2 \text { years) } \\
\text { then } 6 / 12\end{array}$ & - & - & Yes (ICl-SF) & - & Not recorded & $\begin{array}{c}12 / 12 \text { (after } \\
2000-10 / 12 \\
\text { cores taken } \\
\text { at } 9 / 12 \text { ) }\end{array}$ & $\begin{array}{l}\text { Annually (earlier } \\
\text { if a dramatic } \\
\text { rise in PSA or } \\
\text { change in DRE) }\end{array}$ \\
\hline $\begin{array}{l}\text { Royal } \\
\text { Marsden } \\
(15)\end{array}$ & $\begin{array}{c}3 / 12 \\
\text { (year } 1 \text { ), } \\
\text { 4/12 (year } \\
\text { 2) then } \\
\text { every } 6 / 12\end{array}$ & $\begin{array}{c}3 / 12 \text { (year } \\
1 \text { ), } 4 / 12 \\
\text { (year 2) } \\
\text { then every } \\
6 / 12\end{array}$ & - & Yes & - & - & $10-12$ & $24 / 12$ & Every 2 years \\
\hline $\begin{array}{l}\text { University of } \\
\text { Copenhagen } \\
\text { (18) }\end{array}$ & $3 / 12$ & $3 / 12$ & - & - & - & - & $10-12$ & $12 / 12$ & $\begin{array}{c}\text { Variable } \\
\text { depending on } \\
\text { patient risk } \\
\text { (PSAD) }\end{array}$ \\
\hline $\begin{array}{l}\text { St Vincents, } \\
\text { Australia (19) }\end{array}$ & $\begin{array}{c}\text { 6/12 } \\
\text { (3 years) } \\
\text { then } \\
\text { annually }\end{array}$ & $\begin{array}{c}3 / 12 \text { (up to } \\
3 \text { years) } \\
\text { then } 6 / 12\end{array}$ & - & - & - & - & - & $12 / 12$ & $\begin{array}{l}\text { At } 1-2 \text { years } \\
\text { then every } \\
3-5 \text { years } \\
\text { (switched } \\
\text { to watchful } \\
\text { waiting once } \\
\text { age }>75 \text { years/ } \\
\text { life expectancy } \\
<7 \text { years) }\end{array}$ \\
\hline
\end{tabular}

Table 3 (continued) 
Table 3 (continued)

\begin{tabular}{|c|c|c|c|c|c|c|c|c|c|}
\hline Study & $\begin{array}{c}\text { DRE } \\
\text { (frequency } \\
\text { in months) }\end{array}$ & $\begin{array}{c}\text { PSA } \\
\text { (frequency } \\
\text { in months) }\end{array}$ & $\begin{array}{l}\text { Free to total } \\
\text { ratio PSA } \\
\text { (frequency } \\
\text { in months) }\end{array}$ & $\begin{array}{c}\text { General } \\
\text { health } \\
\text { assessment }\end{array}$ & $\begin{array}{c}\text { Urinary } \\
\text { symptoms } \\
\text { assessment }\end{array}$ & Imaging & $\begin{array}{l}\text { Number of } \\
\text { biopsy cores }\end{array}$ & $\begin{array}{c}\text { 1st re- } \\
\text { biopsy } \\
\text { scheduled } \\
\text { (frequency } \\
\text { in months) }\end{array}$ & $\begin{array}{l}\text { Follow- } \\
\text { up biopsy } \\
\text { schedule }\end{array}$ \\
\hline $\begin{array}{l}\text { Goteborg } \\
\text { (20) }\end{array}$ & $3 / 12-6 / 12$ & $3 / 12-6 / 12$ & - & - & - & - & - & No & $\begin{array}{c}\text { Every } 2-3 \text { years } \\
\text { or on clinical } \\
\text { progression }\end{array}$ \\
\hline $\begin{array}{l}\text { Multi- } \\
\text { institutional } \\
\text { Canary } \\
\text { PASS (21) }\end{array}$ & $6 / 12$ & $3 / 12$ & - & Yes & - & - & - & $6 / 12-2 / 12$ & Year 2, 4, 6 \\
\hline \multirow[t]{2}{*}{$\begin{array}{l}\text { Milan (SAINT } \\
+ \text { PRIAS) } \\
(22)\end{array}$} & $\begin{array}{c}\text { 6/12 } \\
\text { (SAINT) }\end{array}$ & $3 / 12$ & - & - & - & - & $\begin{array}{c}\text { Since } 2012, \\
\text { Prostate } \\
\text { volume } \\
\text { dependant } \\
\left(\mathrm{PV}<40 \mathrm{~cm}^{3}\right. \\
=8 ; 40-60 \mathrm{~cm}^{3} \\
=10 ;>60 \mathrm{~cm}^{3} \\
=12)\end{array}$ & $\begin{array}{c}12 / 12 \text { then } \\
24 / 12\end{array}$ & Every 2 years \\
\hline & $\begin{array}{c}\text { 6/12 } \\
\text { (PRIAS) }\end{array}$ & $\begin{array}{l}3 / 12 \text { (up } \\
\text { to } 2 \text { years) } \\
\text { then } 6 / 12\end{array}$ & - & - & - & - & $\begin{array}{c}\text { Prostate } \\
\text { volume } \\
\text { dependant } \\
\left(\mathrm{PV}<40 \mathrm{~cm}^{3}\right. \\
=8 ; 40-60 \mathrm{~cm}^{3} \\
=10 ;>60 \mathrm{~cm}^{3} \\
=12)\end{array}$ & $12 / 12$ & Year $4 \& 7$ \\
\hline
\end{tabular}

PSAD, PSA density; PSADT, PSA doubling time; PSAV, PSA velocity; TRUS, trans-rectal ultrasound; MCL, maximum cancer length; ICI-SF, international conference on incontinence short-form.

recommend serial serum PSA measurements, DRE and surveillance biopsies to check for and identify indications of tumour progression (Table 3).

\section{DRE}

Of the thirteen studies, DRE as part of the surveillance strategy played an important role in nine [MSKCC (10), John Hopkins (11) UCSF (12), University of Miami (14), Royal Marsden (15), University of Copenhagen (UCPH) (18), St Vincent's Australia (19), Goteborg (20) and Canary PASS (21)] with the frequency ranging from 3 to 6 monthly.

\section{PSA}

All studies carried out PSA testing, but again protocols ranged from 3 to 6 monthly. Only MSKCC (10) recommended a 6-monthly free to total ratio PSA as useful.

\section{Prostate re-biopsy}

Eleven studies carried out confirmatory biopsies within a year of initial diagnosis, whilst the Royal Marsden (15) cited acceptability within 2 years of AS initiation and ProtecT (16) required no repeat biopsy. All studies demonstrated differences in the frequency that biopsies were repeated thereafter. Two centres [John Hopkins (11) and University of Miami (12)] routinely biopsied annually, with the others ranging from 2-3 yearly or on clinical progression. Only the ProtecT study (16) did not perform routine and regular re-biopsy. UCSF (12) was the only institution to carry out regular trans-rectal ultrasound without biopsy.

\section{General health assessment}

Regular routine general health assessments were undertaken in two studies [MSKCC (10) and Canary PASS (21)], as a possible criterion for switching to watchful waiting (WW), 
Table 4 Triggers for intervention (treatment or further characterisation)

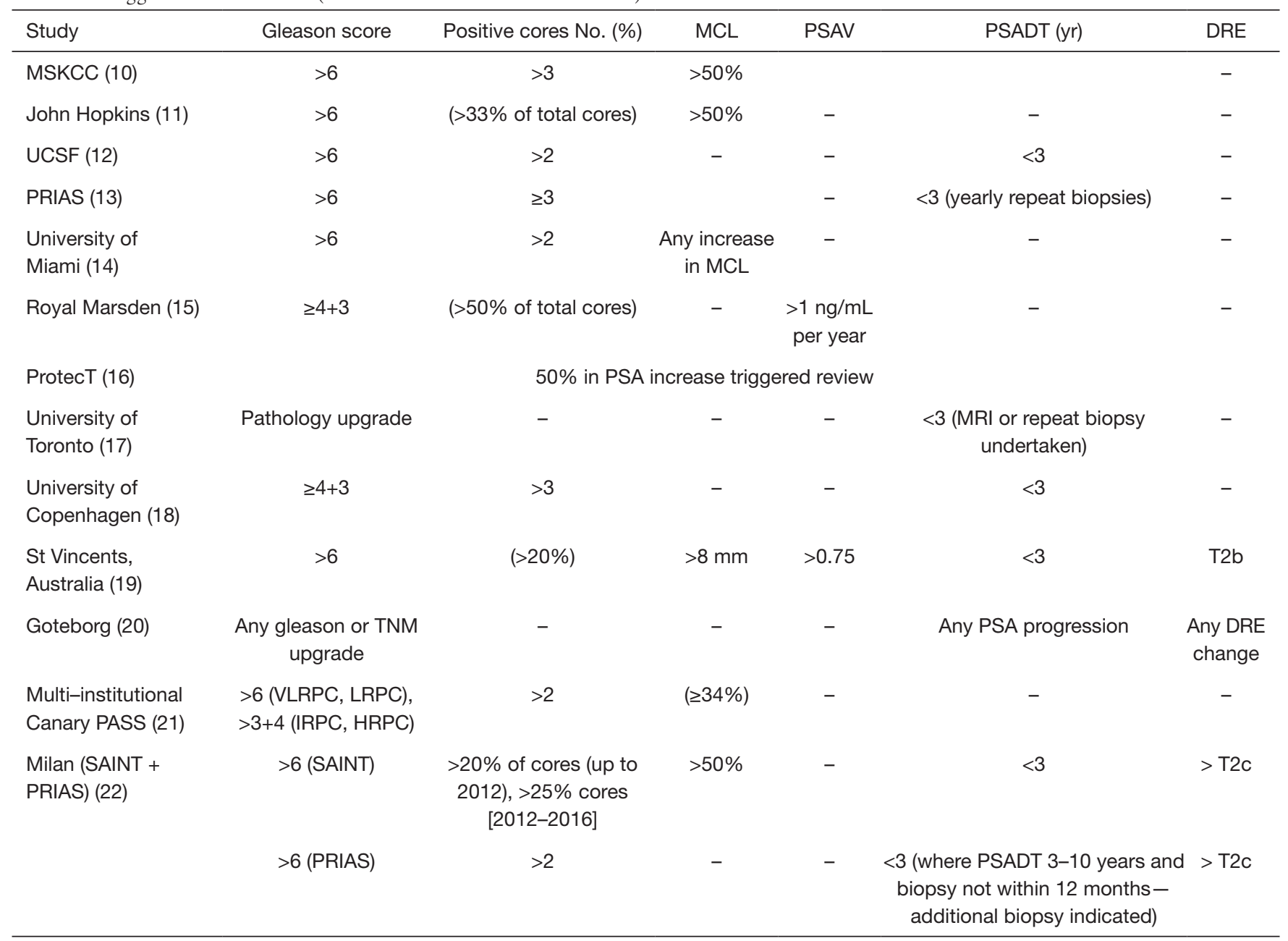

LRPC, low-risk prostate cancer; IRPC, intermediate-risk prostate cancer; MRI, magnetic resonance imaging; MCL, maximum cancer length.

with only MSKCC indicating that they carried out regular lower urinary tract symptom assessment. Two centres [University of Toronto (17) and St Vincent's Australia (19)] indicated that they switched patients from AS to WW at 80 and 75 years old, respectively.

\section{Triggers for intervention}

At 5 years of follow-up, the proportion of men treated ranged from $14 \%$ to $50 \%$ across all of the studies. The proportion of men who developed metastatic disease was low across all studies, in the Johns Hopkins cohort (12) for example; this was recorded as $0.1 \%$ and $0.6 \%$ at 5 and 15 years, respectively. The PC specific mortality rates were also low ranging from $0.2 \%$ to $5.7 \%(10,17)$ (Table 1$)$.
Definitions of disease reclassification and progression differ across national guidelines and the AS cohorts described here are different. Many of the cohorts describe changes in one or multiple criteria for initiation of definitive treatment (Table 4).

\section{Pathology (Gleason score)}

Amongst the 13 cohorts reviewed here, 8 studies [MSKCC (10), John Hopkins (11), UCSF (12), PRIAS (13), University of Miami (14), St Vincent's Australia (19), Canary PASS (21) and Milan (22)] triggered intervention in LRPC if subsequent pathology was Gleason score $>6$. In the Canary PASS LRPC group radical treatment versus continued AS (with re-classification as intermediate-risk) were discussed as options. Two [University of Toronto (17) and Goteborg (20)] 
suggested any pathological upgrade would trigger intervention. Two cohorts [Royal Marsden (15) and UCPH (18)] identified a Gleason score of $\geq 4+3$ as the trigger point. Only Canary PASS (21) and Goteborg (20) gave a weighting depending on very low-risk/low risk (Gleason $>3+3$ ) or intermediate/Highrisk (Gleason $\geq 3+4)$ disease.

\section{Number/percentage of positive cores}

Five of the thirteen studies [MSKCC (10), UCSF (12), PRIAS (13), University of Miami (14) and Milan (22)] maintained that $>2$ cores positive should trigger treatment, with the UCPH (18) extending this to $>3$ cores positive. St Vincent's Australia (19) suggested that cancer found in $>20 \%$ of any positive core should trigger intervention, whilst The Royal Marsden (15) and Johns Hopkins (11) suggested a higher threshold for triggering treatment: $50 \%$ and $33 \%$ respectively. The remaining studies gave no indication of cut-off based on number of cores positive. The maximum cancer length (MCL) was variable, with two centres [MSKCC (10) and John Hopkins (11)] suggesting a cut-off of $50 \%$ and two centres suggesting more conservative numbers; St Vincent's Australia (19) suggesting a cut-off of $8 \mathrm{~mm}$ of cancer and the Canary PASS consortium was set at $\geq 34 \%$. The University of Miami (14) defined any increase in volume of PC and in MCL as their trigger for intervention.

PSA-based triggers for intervention included PSA doubling time (PSAD) and PSA velocity (PSAV). Only two studies suggested PSAV as an important trigger, The Royal Marsden (15) suggesting a PSAV of $>1$ and St Vincent's Australia (19) $>0.75$. PSA doubling time was included in six studies [UCSF (12), PRIAS (13), University of Toronto (17), UCPH (18), St Vincent's Australia (19) and Milan (22)] with a cut-off of 3 years. The Goteborg group (20) defined the trigger as any PSA progression.

\section{Summary of systematic review}

The thirteen AS cohorts included in this review demonstrated a wide variety of descriptions of LRPC. This indicates a clear lack of consensus on defining favourable risk disease, suitability for AS and intervention thresholds.

Patient selection (Table 2): despite all studies agreeing that a clinically localised PC diagnosis was defined as T2 disease and the majority of studies agreeing on a PSA threshold of $<10 \mu \mathrm{g} / \mathrm{L}$ and Gleason score $3+3(3+4$ in intermediate risk disease), there was significant inconsistency in practice when considering pathology (i.e., the number of acceptable positive cores and MCL).

Monitoring protocols (Table 3): all studies agreed on PSA surveillance with a frequency ranging from 3 to 6 monthly and most agreed that a confirmatory biopsy was required within 12 months after AS selection, however, no consensus was reached on the importance and relevance of DRE or rebiopsy strategy.

Triggers for intervention (Table 4): the cohorts described here appear cautious in their definition of disease progression, with low tolerance for increasing PSA defined as "any" or number of positive cores, cancer volume, and/or change in Gleason score. There was no universal agreement on triggers for intervention although, agreement was reached on Gleason score $>6$ in $62 \%$ of studies, number of percentage increase in positive cancer cores was identified in $69 \%$ of the cohorts, MCL and PSA doubling time of $<3$ years was used in $46 \%$ of the studies.

A narrative review performed in 2016 showed that existing guidelines regarding AS for PC vary widely, but predominantly state that the most suitable patients for AS are those with pre-treatment clinical stage T1c or $\mathrm{T} 2$ tumours, serum PSA levels $<10 \mu \mathrm{g} / \mathrm{L}$, biopsy Gleason scores of $\leq 6$, a maximum of two tumour positive biopsy core samples and/or a MCL of $50 \%$ per core sample (44). The heterogeneity in practice demonstrated in this narrative, further highlights the need for a robust collaborative worldwide prospective study to finally determine safe patient selection, monitoring and appropriate triggers for intervention.

\section{The future of AS}

\section{Imaging}

The use of magnetic resonance imaging (MRI) in the context of AS varies between practitioners, countries and healthcare systems. Current European (45) guidance on prostate MRI concentrates on its role in the detection and staging of PC. Little evidence has yet been published supporting more generalised use in the context of AS.

This may explain why only two of the thirteen cohorts reviewed [the Milan arm of the PRIAS study (22) and University of Toronto] used MRI to support AS at the time of reporting. The Milan group used MRI imaging routinely (from 2015) as an adjuvant to the AS selection criteria, opening up AS selection to men with negative MRI scans. No limit was placed on number of positive cores in patients with negative MRI's or where targeted biopsy shows 
$3+3$ disease only. The University of Toronto used MRI as a conduit to triggering intervention. Where patients had a PSADT of $<3$ years, MRI and/or repeat biopsy was used to clarify the need for treatment.

In 2015 a systematic review of MRI use in AS found only seven studies addressing MRI reliability in relation in selecting patients for AS using biopsy correlation and two studies focused on the use of repeat MRI in AS (46). This review was hampered by the small number of patients in the included studies as well as the low number of studies. It was concluded that MRI could detect clinically significant PC, however as of yet MRI cannot be considered as an alternative to repeat biopsy in long-term monitoring on AS without further evidence from robust prospective studies.

Despite the paucity of evidence, in 2014 the UK National Institute for Heath and Care Excellence (NICE) PC guidelines (8) suggested a role for MRI in AS, but without any guidance on the criteria for radiological significance and progression. With this in mind, the European School of Oncology recently reported the PRECISE recommendations (47) for MRI usage in AS, with the aim of facilitating the development of a robust evidence base for documenting changes in prostate MRI findings in men on AS over time. This checklist will allow for better assessment of the natural history of MRI change in men on AS.

\section{The role of nomograms in AS}

Nomograms have been successfully used and integrated into healthcare setting as an assist to both patients and clinicians in establishing risk and aiding decision making. There is widely accepted usage of nomograms in PC diagnosis $(48,49)$. However, predictive nomograms for indolent disease in the context of AS have been less successful (50). In 2016 Venderbos and colleagues studied participants of the European Randomized study of Screening for PC (ERSPC) (51) to establish whether a probabilistic nomogram could improve patient selection for AS compared to a rule based criteria. They reviewed men initially diagnosed with histopathological indolent PC at radical prostatectomy [defined as $\mathrm{pT} 2$, Gleason pattern $\leq 3$ and tumour volume (TV) $\leq 0.5 \mathrm{~mL}$ or $\mathrm{TV} \leq 1.3 \mathrm{~mL}$ ] to develop an existing nomogram to provide probability-based data and compared this to rule-based selection according to the PC Research International: Active Surveillance (PRIAS) (13), University of Toronto (17), and Johns Hopkins (11) criteria. The performance of the nomogram, using the Johns Hopkins (11) and PRIAS (13) rule-based criteria's, were found to be comparable and could prove a good alternative to rigid rule-based surveillance protocols where patients request more information on probability of progression to make informed decisions on treatment.

\section{Global action plan PC active surveillance (GAP3) initiative}

Although AS has evolved to a broadly accepted management strategy for men diagnosed with LRPC, this systematic review of worldwide AS practices confirms there is little consensus on inclusion criteria, surveillance schedules and intervention thresholds. Also, variation in AS semantics used in literature and guidelines could lead to confusion.

To address these issues, the Movember Foundation launched within their Global Action Plan Prostate Cancer Active Surveillance initiative (GAP3) in August 2014 (52). To date, GAP3 has united as many as 25 institutions, hospitals and research centres from the USA, Canada, Australia, Singapore, Japan, Korea, UK, Ireland, the Netherlands, France, Sweden, Finland, Switzerland, Italy and Spain. The primary aim of the GAP3 initiative is to create global consensus on the selection and monitoring of men with low risk PC, ultimately resulting in worldwide uniform guidelines.

Within the GAP3 initiative, the largest centralized PC AS database to date was constructed by combining patient data from 25 established AS cohorts worldwide. This database currently comprises clinical, marker-related and imaging data on more than 15,000 patients. Multiple data analyses of this unique global data set are currently ongoing focussing on three main questions regarding AS: which patients are most suitable for AS, what is the most appropriate follow-up schedule and what is the right moment to switch to active treatment? Based on these results, a peer reviewed publication on consensus guidelines is expected in 2019.

In addition, the GAP3 programme is performing a centralized pathology review of randomly selected biopsies. Preliminary results confirm consistent biopsy quality and grading across the different centres, which would enable data analyses without correction. Moreover, a panel of leading PC specialists in the field of AS was convened to overcome the AS semantic heterogeneity in literature and guidelines (43). By using a modified Delphi consensus procedure including a three-round sequence of online questionnaires and a face-to-face consensus meeting, formal consensus was reached for all 61 individual terms.

Movember has recently allocated additional funding to maintain the database and update the clinical data 
annually with a special focus on MRI, quality of life and genomics data. MRI is becoming an increasingly important technology for the management of AS. GAP3 aims to also assess the value of MRI with respect to lesion definition and changes over time. Conclusions based on the analyses of patient series published to date are limited due to small size cohorts. Therefore, the need to combine these data is imperative to assess the value of MRI. This also holds true for assessing the use of genomic markers, as well as quality of life in the decision to initially pursue AS rather than active treatment.

In summary, analyses of global AS data within GAP3 will further elucidate the optimal inclusion criteria, surveillance schedules and intervention thresholds and result in more uniform AS guidelines.

This will enable clinicians to more confidently identify men who are suitable for AS and to also decide whose PCa has progressed and will, therefore, require treatment. In addition, this will reassure men of making the most informed treatment decision for their type of disease.

\section{Conclusions}

In the last 15 years large cohort studies have progressed the definition of safe AS. Collaborations between institutions [ProtecT (UK) (16) and Canary PASS (US) (21)] and even countries [The PRIAS study (13)] have contributed to our increasing confidence in AS and a demonstrable increase in the number of men selecting AS.

This systematic review shows that AS is being applied. However, implementation of successful AS programmes worldwide needs to reduce the over treatment of PC as well as creating a safety net for men incorrectly diagnosed with indolent disease. Currently, the general Urologist and/ or Oncologist may struggle to manage these patients with any degree of confidence, which may explain variations in practice. This confidence requires robust data from large cohorts with long follow-up, such as collected within the GAP3 initiative, to create global consensus on inclusion criteria, surveillance schedules and intervention thresholds.

\section{Acknowledgements}

Funding: Sigrid Carlsson is supported in part by a Cancer Center Support Grant from the National Cancer Institute made to Memorial Sloan Kettering Cancer Center (P30CA008748), a SPORE grant from the National Cancer Institute to Dr. H. Scher (P50-CA092629), a grant from the
National Cancer Institute as part of the Cancer Intervention and Surveillance Modeling Network (U01CA199338-02) and the David H. Koch prostate cancer research fund.

\section{Footnote}

Conflicts of Interest: The authors have no conflicts of interest to declare.

\section{References}

1. Wong MC, Goggins WB, Wang HH, et al. Global Incidence and Mortality for Prostate Cancer: Analysis of Temporal Patterns and Trends in 36 Countries. Eur Urol 2016;70:862-74.

2. Network NCI. Cancer incidence, males, ICD10 C61: Prostate, 2008-2010. National Cancer Intelligence Network (NCIN), UK Cancer Information Service (UKCIS). UKCIS. 2010.

3. Van Hemelrijck M, Garmo H, Wigertz A, et al. Cohort profile update: the National Prostate Cancer Register of Sweden and Prostate Cancer data Base-a refined prostate cancer trajectory. Int J Epidemiol 2016;45:73-82.

4. Cooperberg MR, Carroll PR. Trends in Management for Patients With Localized Prostate Cancer, 1990-2013. JAMA 2015;314:80-2.

5. Dall'Era MA. The economics of active surveillance for prostate cancer. Curr Opin Urol 2013;23:278-82.

6. Eldefrawy A, Katkoori D, Abramowitz M, et al. Active surveillance vs. treatment for low-risk prostate cancer: a cost comparison. Urol Oncol 2013;31:576-80.

7. Bruinsma SM, Bangma CH, Carroll PR, et al. Active surveillance for prostate cancer: a narrative review of clinical guidelines. Nat Rev Urol 2016;13:151-67.

8. NICE. NICE Guidelines for the managment of Active Surveillance. NICE. 2014. Accessed 20 March 2014.

9. Heidenreich A, Bastian PJ, Bellmunt J, et al. EAU guidelines on prostate cancer. Part 1: screening, diagnosis, and local treatment with curative intent-update 2013. Eur Urol 2014;65:124-37

10. Adamy A, Yee DS, Matsushita K, et al. Role of prostate specific antigen and immediate confirmatory biopsy in predicting progression during active surveillance for low risk prostate cancer. J Urol 2011;185:477-82.

11. Tosoian JJ, Mamawala M, Epstein JI, et al. Intermediate and Longer-Term Outcomes From a Prospective ActiveSurveillance Program for Favorable-Risk Prostate Cancer. J Clin Oncol 2015;33:3379-85. 
12. Welty CJ, Cowan JE, Nguyen H, et al. Extended followup and risk factors for disease reclassification in a large active surveillance cohort for localized prostate cancer. J Urol 2015;193:807-11.

13. Bul M, Zhu X, Valdagni R, et al. Active surveillance for low-risk prostate cancer worldwide: the PRIAS study. Eur Urol 2013;63:597-603.

14. Soloway MS, Soloway CT, Eldefrawy A, et al. Careful selection and close monitoring of low-risk prostate cancer patients on active surveillance minimizes the need for treatment. Eur Urol 2010;58:831-5.

15. Selvadurai ED, Singhera M, Thomas K, et al. Mediumterm outcomes of active surveillance for localised prostate cancer. Eur Urol 2013;64:981-7.

16. Hamdy FC, Donovan JL, Lane JA, et al. 10-Year Outcomes after Monitoring, Surgery, or Radiotherapy for Localized Prostate Cancer. N Engl J Med 2016;375:1415-24.

17. Klotz L, Vesprini D, Sethukavalan P, et al. Long-term follow-up of a large active surveillance cohort of patients with prostate cancer. J Clin Oncol 2015;33:272-7.

18. Thomsen FB. Active surveillance strategy for patients with localised prostate cancer: criteria for progression. Dan Med J 2015;62. pii: B5005.

19. Thompson JE, Hayen A, Landau A, et al. Mediumterm oncological outcomes for extended vs saturation biopsy and transrectal vs transperineal biopsy in active surveillance for prostate cancer. BJU Int 2015;115:884-91.

20. Godtman RA, Holmberg E, Khatami A, et al. Longterm Results of Active Surveillance in the Goteborg Randomized, Population-based Prostate Cancer Screening Trial. Eur Urol 2016;70:760-6.

21. Newcomb LF, Thompson IM Jr, Boyer HD, et al. Outcomes of Active Surveillance for Clinically Localized Prostate Cancer in the Prospective, Multi-Institutional Canary PASS Cohort. J Urol 2016;195:313-20.

22. Marenghi C, Alvisi MF, Palorini F, et al. Elevenyear management of prostate cancer patients on active surveillance: what have we learned? Tumori 2017;103:464-74.

23. Volk RJ, McFall SL, Cantor SB, et al. 'It's not like you just had a heart attack': decision-making about active surveillance by men with localized prostate cancer. Psychooncology 2014;23:467-72.

24. Xu J, Neale AV, Dailey RK, et al. Patient perspective on watchful waiting/active surveillance for localized prostate cancer. J Am Board Fam Med 2012;25:763-70.

25. Loeb S, Curnyn C, Fagerlin A, et al. Qualitative study on decision-making by prostate cancer physicians during active surveillance. BJU Int 2017;120:32-9.

26. Davison BJ, Breckon E. Factors influencing treatment decision making and information preferences of prostate cancer patients on active surveillance. Patient Educ Couns 2012;87:369-74.

27. Gorin MA, Soloway CT, Eldefrawy A, et al. Factors that influence patient enrollment in active surveillance for lowrisk prostate cancer. Urology 2011;77:588-91.

28. O'Callaghan C, Dryden T, Hyatt A, et al. 'What is this active surveillance thing?' Men's and partners' reactions to treatment decision making for prostate cancer when active surveillance is the recommended treatment option. Psychooncology 2014;23:1391-8.

29. Mishra MV, Bennett M, Vincent A, et al. Identifying barriers to patient acceptance of active surveillance: content analysis of online patient communications. PLoS One 2013;8:e68563.

30. Loeb S, Folkvaljon Y, Curnyn C, et al. Uptake of Active Surveillance for Very-Low-Risk Prostate Cancer in Sweden. JAMA Oncol 2017;3:1393-8.

31. Liu J, Womble PR, Merdan S, et al. Factors Influencing Selection of Active Surveillance for Localized Prostate Cancer. Urology 2015;86:901-5.

32. Filson CP, Schroeck FR, Ye Z, et al. Variation in use of active surveillance among men undergoing expectant treatment for early stage prostate cancer. J Urol 2014;192:75-80.

33. Anandadas CN, Clarke NW, Davidson SE, et al. Early prostate cancer--which treatment do men prefer and why? BJU Int 2011;107:1762-8.

34. Wilcox CB, Gilbourd D, Louie-Johnsun M. Anxiety and health-related quality of life (HRQL) in patients undergoing active surveillance of prostate cancer in an Australian centre. BJU Int 2014;113 Suppl 2:64-8.

35. Parker PA, Davis JW, Latini DM, et al. Relationship between illness uncertainty, anxiety, fear of progression and quality of life in men with favourable-risk prostate cancer undergoing active surveillance. BJU International 2016;117:469-77.

36. UK CR. Prostate Cancer Statistics. Available online: http://www.cancerresearchuk.org/cancer-info/cancerstats/ types/prostate/

37. Auffenberg GB, Lane BR, Linsell S, et al. Practice- vs physician-level variation in use of active surveillance for men with low-risk prostate cancer: Implications for collaborative quality improvement. JAMA Surg 2017;152:978-80. 
38. Weerakoon M, Papa N, Lawrentschuk N, et al. The current use of active surveillance in an Australian cohort of men: a pattern of care analysis from the Victorian Prostate Cancer Registry. BJU Int 2015;115 Suppl 5:50-6.

39. Victorian Prostate Cancer Clinical Registry - Five year report. Available online: http://pcr.registry.org.au

40. Louis AS, Kalnin R, Maganti M, et al. Oncologic outcomes following radical prostatectomy in the active surveillance era. Can Urol Assoc J 2013;7:E475-80.

41. Huland H, Graefen M. Changing Trends in Surgical Management of Prostate Cancer: The End of Overtreatment? Eur Urol 2015;68:175-8.

42. Mitsuzuka K, Koga H, Sugimoto M, et al. Current use of active surveillance for localized prostate cancer: A nationwide survey in Japan. Int J Urol 2015;22:754-9.

43. Bruinsma SM, Roobol MJ, Carroll PR, et al. Expert consensus document: Semantics in active surveillance for men with localized prostate cancer [mdash] results of a modified Delphi consensus procedure. Nat Rev Urol 2017;14:312-22.

44. Bruinsma SM, Zhang L, Bangma CH, et al. Worldwide variation in determinants for inclusion and follow-up in active surveillance for low-risk prostate cancer: results of the Movember Foundation's Global Action Plan Prostate Cancer Active Surveillance (GAP3) initiative. J Urol 2017;97:e519.

45. Mottet N, Bellmunt J, Bolla M, et al. EAU-ESTROSIOG Guidelines on Prostate Cancer. Part 1: Screening,

Cite this article as: Kinsella N, Helleman J, Bruinsma S, Carlsson S, Cahill D, Brown C, Van Hemelrijck M. Active surveillance for prostate cancer: a systematic review of contemporary worldwide practices. Transl Androl Urol 2018;7(1):83-97. doi: 10.21037/tau.2017.12.24
Diagnosis, and Local Treatment with Curative Intent. Eur Urol 2017;71:618-29.

46. Schoots IG, Petrides N, Giganti F, et al. Magnetic resonance imaging in active surveillance of prostate cancer: a systematic review. Eur Urol 2015;67:627-36.

47. Moore CM, Giganti F, Albertsen P, et al. Reporting Magnetic Resonance Imaging in Men on Active Surveillance for Prostate Cancer: The PRECISE Recommendations-A Report of a European School of Oncology Task Force. Eur Urol 2017;71:648-55.

48. Korets R, Motamedinia P, Yeshchina O, et al. Accuracy of the Kattan nomogram across prostate cancer risk-groups. BJU International 2011;108:56-60.

49. Shariat SF, Kattan MW, Vickers AJ, et al. Critical review of prostate cancer predictive tools. Future oncology 2009;5:1555-84.

50. Mamawala MM, Rao K, Landis $\mathrm{P}$, et al. Risk prediction tool for grade re-classification in men with favourablerisk prostate cancer on active surveillance. BJU Int 2017;120:25-31.

51. Venderbos LD, Roobol MJ, Bangma CH, et al. Rule-based versus probabilistic selection for active surveillance using three definitions of insignificant prostate cancer. World J Urol 2016;34:253-60.

52. Bruinsma SM, Zhang L, Roobol MJ, et al. The Movember Foundation's GAP3 cohort: A profile of the largest global prostate cancer active surveillance database to date. BJU Int 2017. [Epub ahead of print]. 